\title{
CORRELAÇĀO LITOESTRATIGRÃFICA DAS ROCHAS DO GRUPO ITARARÉ NO RIO GRANDE DO SUL E SUL DE SANTA CATARINA: UMA ANÁLISE PRELIMINAR
}

Ana Emília Mendes Piccoli (IG/UFRGS)

Ricardo Cunha Lopes (CPRM)

Michael Holz (IG/UFRGS)

O trabalho tem como principal objetivo a identificaça da sequencia sedimentar pertencente ao Grupo Itararé (Permiano Inferior, da Bacia do Paranáno RS e sul de SC, ao longo de duas seços estratigraficas, com direço NE-SW. Estas foram elaboradas a partir de áreas mais profundas da bacia (SC) até os paleovales identificados na borda sul, junto ao Escudo Sul-Rio-Grandense (BOSSI \& PICCOLI, 1979; LOPES et alii,1986; PICCOLI et alii, 1983, HOLZ et alii, 1986). Uma seçăo (Fig.1) é de posicionamento mais interno na bacia, enquanto a segunda acompanha a sua borda, permitindo o reconhecimento das variaços faciológicas.

A correlaça litoestratigráfica foi realizada com base em dados de perfis de afloramentos e de sondagens, com suas curvas de perfilagem de raio gama sendo definido como datum de correlaço o contato entre a sedimentaço pelitico-carbonática da Formaçăo Irati com a pelitico-arenosa da Formaçăo Palermo.

palinomortos daco dados de bioestratigraficos de DAEKON \& QUADROS (1970), e as biozonas de MARQUES-TOIGO ( 1988 ) e KARQUES-TOIGO et ali i ( 1989 ).

As secōes de correlaço (Figs. 1 e 2) mostraram os principais depocentros de sedimentaça das rochas da unidade na regia abrangida pelos perfis. Nota-se claramente um aprofundamento da bacia em direçäo a $\mathbf{M}-\mathbf{N E}$ do Rio Grande do Sul e Sul de Santa Catarina, com deposiça de espessa sequencia encontrada nos perfis LA-1-SC, 1 MA-1-RS e 1 HV-1-SC. Na porça centro-norte do RS (AO-1-RS) desaparecem as rochas do Itararé e a Formaç đo Rio Bonito recobre o Escudo Sul-Rio-Grandense e as unidades eo-paleozóicas em "onlap", definindo a ocorrencia de um alto do embasamento nesta area a época Itararé(Fig.1).

Da porça central do RS em direçăo a oeste (AL-ST-1-RS) há Iradual acréscimo na espessura, com a bacia mostrando um aprofundamento acentuado (Fig. 1 ). 0 mesmo se verifica na porço centro-leste do estado, onde se identifica o paleovale LearoMariana Pimentel ( $A B-06-R S$ ) e afloramento Korro Papaléolem que ocorrem porcós representativas de rochas pertencentes ao Grupo I tarare (Fig.2).

A sequencia sedientar desta unidade estratigrafica apresenta na base facies de ritaitos, silitios e diamictios (algumas camadas reconhecidas como tilitos) e,superiormente, facies de pelitos escuros (cinzas a pretos) e claros ( no topo). DELANEY \& GONI ( 1963) denominaram a facies inferior de Suspiro, reconhecida como de origem glacial, e a superior de Budó, de origen marinha. Os diamictitos e tilitos da Fácies Suspiro mostram matriz pelitica dominando sobre os clastos grosseiros (quartzo, rochas graniticas, sedimentares e metamóricas) que podem ser facetados e estriados. Os ritmitos săo formados por 


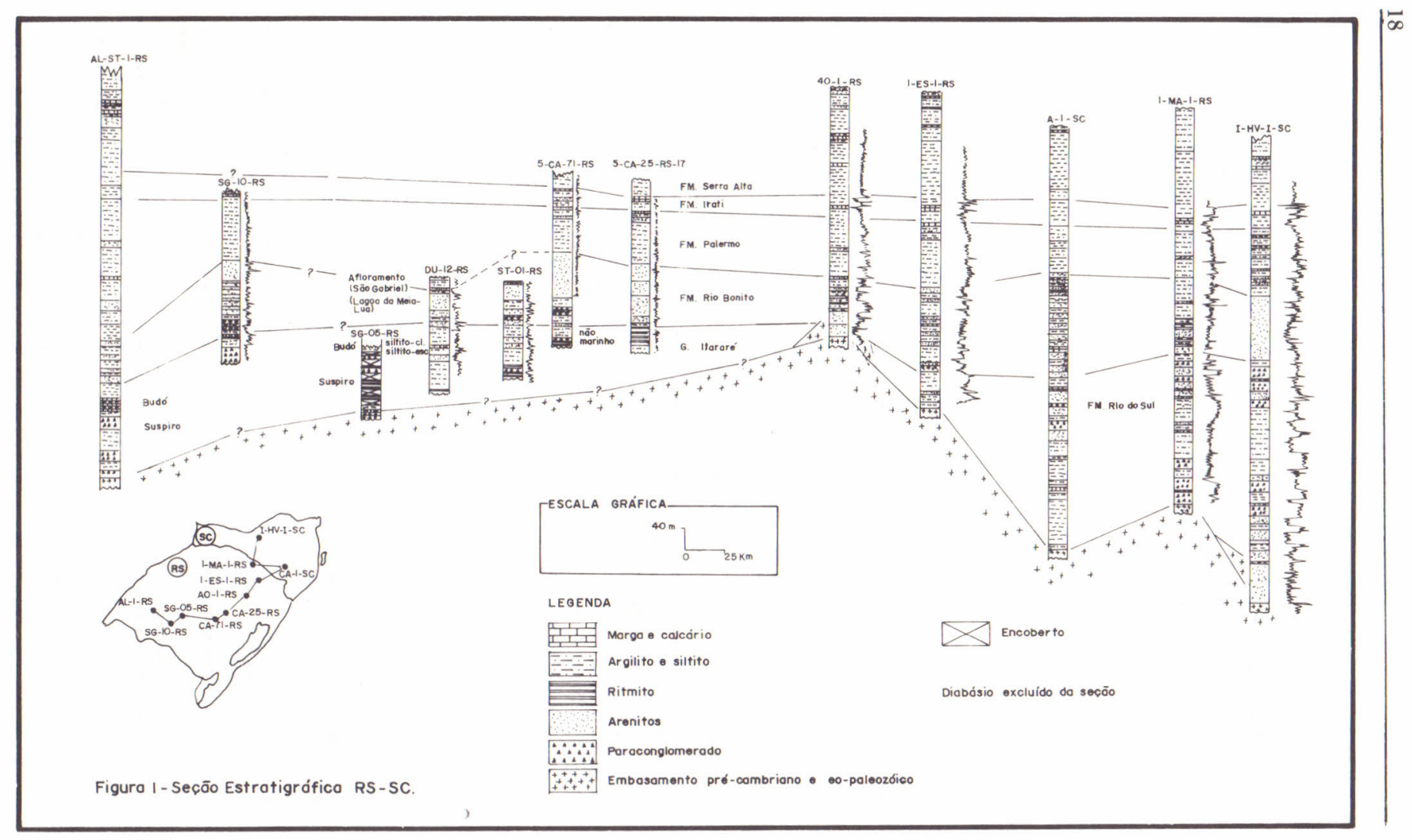


estratos tabulares de arenitos finos e pelitos e apresentam seixos pingados.

Ma regiă de Să Gabriel (PICCOLI, 1989), Cachoeira do Sul e Bagé (TOMAZELli \& SOLIANI JR., 1982) săo encontradas estrias de origem glacial em camadas de diamictitos associadas a ritmitos. Nas duas primeiras areas, ocorrem ainda blocos erraticos de granito, arredondados e com aspecto polido. Esta fácies é encontrada em todos os perfis estudados, localmente apresenta pequenas variaçôs.

A Fácies Budó, da porçăo superior da unidade nas regiớs oeste e centro-oeste do RS, nă pode ser identificada na maioria dos perfis estudados. Na sondagem AL-ST-1-RS e no afloramento sao Gabriel foram identificados fósseis marinhos nas camadas tabulares de pelito preto da base desta sequencia e de pelito cinza claro rosado de aspecto porcelanico do topo (PICCOLI, 1989). Na faixa abrangida pela correlaça estratigráfica esta litofacies é registrada com certeza até próximo à cidade de São Gabriel.

Em direça a regia central e norte do estados ST-01-RS, AB-06-RS, Korro Papaléo-Figs. 1 e 2 ) a sedimentaça do topo do Itararé nå apresenta a mesma composiço. Deixaram de ser identificadas na área abrangida pelas seços, as rochas que compreendem a Fácies Budó. Ocorre a Facies Suspiro, englobando a 1 as rochas depositadas em ambiente continental glacial, pró periglacial(PICCOLI et alii, 1983; PAIM et alii, 1983).

Esta, mostra conglomerados e ritmitos na base, recobertos por pelitos escuros e arenitos finos com laminaça ondulada $e$ "climbing ripples", representando deposiça em ambiente de prodelta e frente deltáica (Fig.2). Houve o desenvolvimento de um delta lacustre dominado por um sistema fluvial. 0 sistema fluvial se implanta posteriormente e vai constituir as rochas da Formaça Rio Bonito ( $P$ ICCOLl et alii, op.cit.; PAIK et alii, op.cit.).

Ao sul de Santa Catarina, regi Io mais profunda da bacia (Fig.1), dominam as facies de diamictitos e ritmitos com ocorrencia de arenitos secundariamente, identificando-se uma deposiça em ambiente glacial, glacio-marinho predominante, com toda uma associaça de subambientes continentais lacustres (MARQUES-TOIGO et alii, 1989) fluviais e marinhos. Estas rochas săo relacionadas à Formaçăo Rio do Sul (SCHNEIDER et alii, 1974). A implantaça do sistema deltáco que corresponde a Formaça Rio Bonito parece dar-se imediatamente sobre a facies de diamictitos e pelitos depositada sob condiços de clima glacial que persistiu até a sedimentaçăo da sequência de topo da Formaça Rio do Sul.

Tratando-se este trabalho de uma analise preliminar, é possfvel comparar-se as rochas do Grupo Itararé (SCHNEIDER et alii, op.cit.) no RS identificadas como Facies Suspiro (glacial)

e Budó (marinho)por DELANEY \& GOñ (1963) com as da Formaçăo Rio do Sul (SCHNEIDER et alii, op.cit.)em SC. A correlaça estratigrafica definitiva requer pesquisas mais detalhadas as quais sao a proposiçao original do projeto sobre o Grupo Itararé no RS e em SC.

FRANÇA \& POTTER ( 1988 ) propôem denominar-se estas rochas como membros Chapéu do Sol e Rio do Sul da Formaça Taciba, unidade superior do Grupo Itarare. Os autores do presente trabalho na identificam estas unidades compostas essencialmente por "lamitos seixosos e raros corpos arenosos" nas seços de correlaçăo realizadas. A denominaçăo tampouco poderá ser aceita, uma vez que existem nomes propostos anteriormente.

Utilizando como subsidios trabalhos anteriores $e$ as seços de correlaça litoestratigráfica realizadas, podera ser delineada, em carater preliminar, a paleogeografia das regios abrangidas pelo trabalho ápoca Itararé, a qual veio a produzir as variaçoses de facies identificadas.

A sedimentaça era, sem dúvida, condicionada por altos do embasamento que cercavam paleovales profundos, semelhantes a 


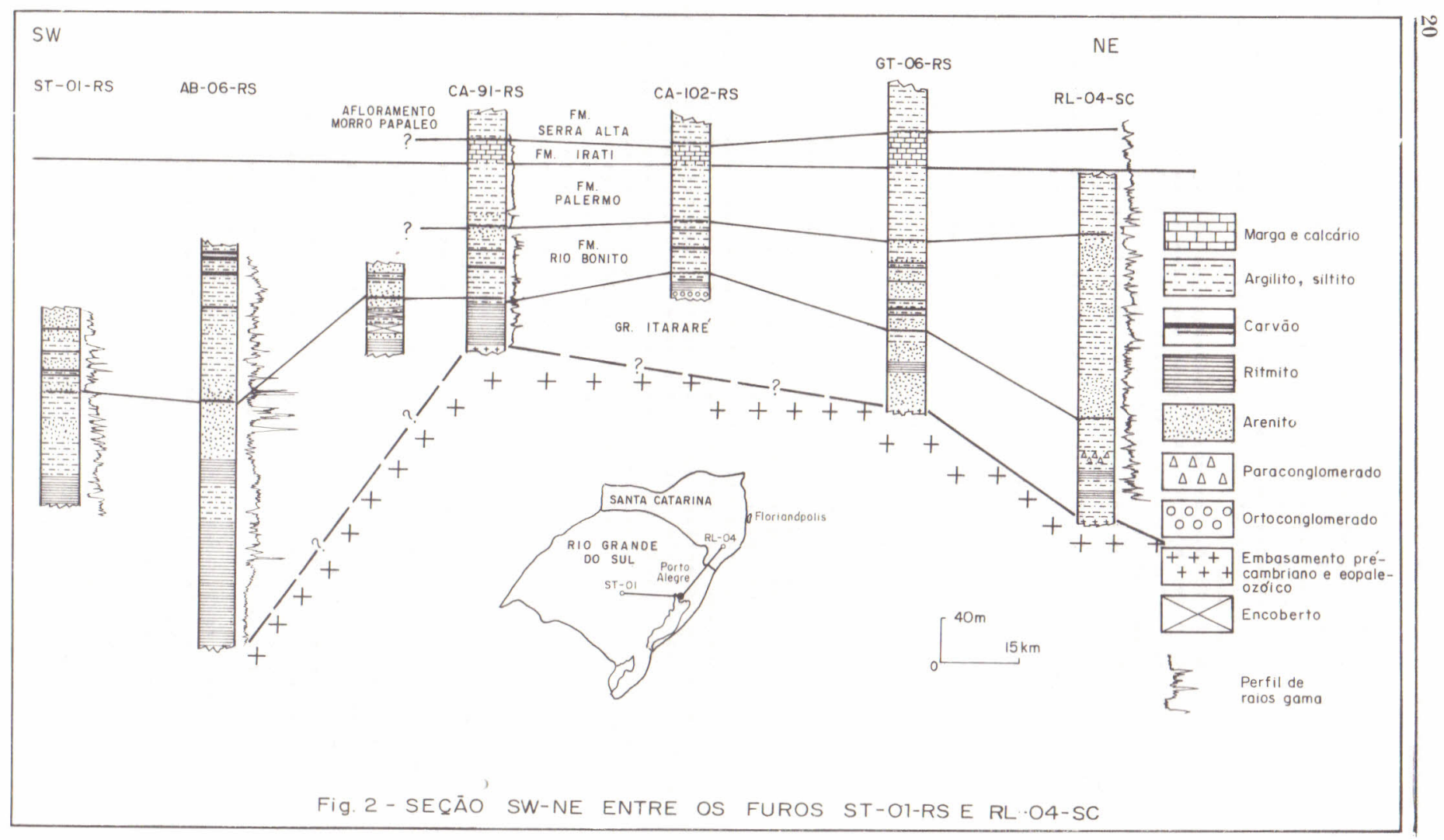


"fiordes", junto a areas elevadas e uma costa relativamente recortada, en clima glacial.

As regios elevadas possuiam geleiras que avançavam recuavam de acordo com épocas de maior ou menor frio A partir daf ocorria o desenvolvimento de ambientes próglaciais e periglaciais dentro de um contexto glacio-marinho e glaciocontinental.

Junto aos altos do embasamento ocorriam conglomerados e arenitos como depositos de leques aluviais e fluviais entrelaçados. Nas áreas rebaixadas, formaram-se lagos sedimentando ritmitos com seixos pingados originados por "icebergs". Tilitos e pavimentos estriados eram produzidos diretamente pelas geleiras em seu avanço e recuo ao longo dos vales.

E Provável que haja uma entrada do mar pelo SW do Rio Grande do Sul e outra por Santa Catarina ( $F i g .1$ ) condicionando a deposiça de rochas como pelitos tabulares com fósseis marinhos produzidos por correntes densas. A transgressa marinha originada pelo aumento do nivel do mar, determinado pelo degelo a partir da melhoria climatica no Artinskiano, passa a dominar em algumas regiơs do RS ( $S W$ da seça 1 até Sao Gabriel). Em regioses como o centro-leste do RS,este episodio condicionou,em ambiente continental, a formaça de deltas lacustres. Ao sul de SC, área onde ha um aprofundamento da bacia, os deltas se desenvolveram em regioes proximas ao mar, persistindo a influencia glacial até topo da Formaça Rio do Sul.

A idade destas rochas no RS e SC obtida através de analise falinológica e a do periodo Permiano Inferior, andares Sakmariano-Artinskiano (MARQUES-TOIGO, 1988; MARQUES-TOIGO e? alii, 1989). Corresponde a biozona Cannaropollis korbaensis, subzonaprotohaploxypinus goraiensis de MARQUES-TOIGO, op.cit.

De acordo com DAEMON \& QUADROS (1970) a sequencia sedimentar do Grupo Itararé em SC abrangeria os intervalos bioestratigráficos G,H1, H2,H3 e I1, que datam os andares do Stefaniano a base do Kunguriano. A porça basal da unidade nao esta presente nas seçós estudadas.

As dataços acima no concordam integralmente com o

trabalho de FRANGA * POTTER (1988) que eleva a idade da Formaço Taciba até o intervalo I4 de DAEHON QUADROS (op.cit.) o qual abrange a parte superior do andar Kunguriano.

Bibliografia

EOSSI,G.E \& FICCOL1, A.E.M. 1979. Interpretaçós paleogeográficas

na Bacla do Parana, Nordeste do Rio Grande do Sul. I - Grupo Itarare. In: SIMPósIO REgIONAL DE GEOLOGIA, 2. Atas. Rio Claro, SF, 1979, 1:157-74.

DAEHON,R.F. * QUADROS,L.P. 1970. Bioestratigrafia do Neopaleozoico da Bacia do Parana. In: CONGREsso BRASILEIRo DE GEOLOGIA, 24, Bras11ia, DF, 1970. Anais. Brasilia, SBG, 1970. P. 359-412.

DELANEY, P.J.U. G0ñl, J.c. 1963. Correlaçao preliminar entre as formacoles gonwanicas do Urugual e Rio Grande do Sul, Brasil. Boletim Paranaense de Geografia, Curitiba, 8/9:3-21.

FRANGA, A.E. \& FOTTER, P.E. 1988. Estratigrafia, ambiente deposioional e analise de reservatorio do Grupo ltarare (Fermo-Carbonifero), Bacla do Parana (Parte 1). B.Geoci.Petrotras,kio de Janeiro, $2(2 / 4): 147-191$.

GUERRA-SOMMER, M.; FICCOLI, A.E.H.; MARQUES-TOIGO,M.; SALDANHA FILHO, P.C. 1985. Estudos 1 átegrados de icnocenose associada molde de invertebrado e palinologia em varuitos do Grupo Itarare (Fermiano Inferior do Rio Grande do sul). In: CONGRESSO BRASILEIFO DALENTOLOGIA, Fortaleza. Anais... (no prelo).

HOLZ,M.; PICCOLI, A.E.M.; UIEIRA, F.E. 1986. Análise estratigrafica das bacias carboniferas do nordeste do estado do Rio Grande to Sul. 'ravatal-Morungava, Chico Loma e Santa 
Terezinha. In: CONGRESSO BRASILEIRO DE GEOLOGIA, 34, Goiania, 1986. Anais. Goiania, SBG. v.1, P.177-90.

LOPES,R.C.; LAUINA, E.L.; SIGNORELLI,M. 1986. Facies sedimentares e evoluça paleoambiental do Supergrupo Tubarao na Borda Leste da Bacia do Paraná. Uma seção regional nos estados do Rio Grande do Sul e Santa Catarina. In: CONGRESSO BRASILEIRO DE GEOLOGIA, 34. Goiania, 1986. anais, Goiania, SBG. v.1, P. 206-18.

MARQUES-TOIGO, K. 1988.Palinulogia, bioestratigrafia e paleoecologia do Noepaleozóico da Bacia do Paraná nos estados do Rio Grande do Sul e Santa Catarina, Brasil. Porto Alegre, Curso de

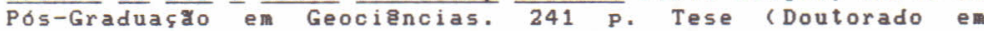
Geociências), Instituto de Geociências, UFRGs.

KARQUES-TOIGO,M.; DIAS-FABR 1 CIO,M.E.; GUERRA-SOMMER, K.; CAZZULOKLEPZIG,H.; PICCOLI,A.E.H. 1989. Afloramentos da área de Trombudo Central, Permiano Inferior, Santa Catarina: Palinologia, icnologia e sedimentologia. In: COKGRESSO BRASILEIRO DE PALEONTOLOGIA, 11, Curitiba, 1989. Resumo das Comunicacoes. Sociedade Brasileira de Paleontologia, P. 43-44.

PAIM,P.S.G.; PICCOLI,A.E.M.; SARTURI,J.A.D.; HOLZ, K.; MUNARO,P.; GRANITOFF, $w$. 1983. Evoluça paleogeográfica do Supergrupo Tubarao na area de Mariana Pimentel-Faxinal, Gualba, RS. In: SIMPOSIO SUL-BRASILEIRO DE GEOLOGIA, 1, Porto Alegre, 1983. Atas, Porto Alegre, SBG, Núcleo RS/SC. P.140-59.

PICCOLI,A.E.M.; PAIM,P.S.G.; SARTURI,J.A.D.; HOLZ,M.; MUNARO,P.;GRANITOFF, W. 1983. Geologia do Supergrupo Tubarao na regia de Mariana Pimentel-Faxinal, Municlpio de Guaba, RS. In: SIMPóSIO SUL-BRASILEIRO DE GEOLOGIA, 1, Porto Alegre, 1983. Atas, Porto Alegre, SBG Nucleo RS/SC. P. 125-139.

PICCOLI, A.E.M. 1989. Relaça estratigráfica entre as fácies Budo e Suspiro (Grupo Itararé) nas folhas de Vila Nova, Lagoa da Meia Lua e Suspiro, RS. Pesquisas, Porto Alegre, n.22, p.4551.

SCHNEIDER,R.L.; MUHLMANN, H.; TOHHASI,E.; MEDEIROS, R.A.; DAEMON,R.K.; NOGUEIRA, A.A. 1974. Revisăo estratigráfica da Bacia do Paraná. In: CONGRESSO BRASILEIRO DE GEOLOGIA, 28, Porto Alegre. Anais, Porto Alegre, SBG. v.1., p. 41-65.

TOMAZELLI,L.J. \& SOLIAMI JR., E. 1982. Evidência de atividade glacial no Paleozóico Supereior do Rio Grande do Sul, Brasil. In: CONGRESSO BRASILEIRO DE GEOLOGIA, 32, Salvador.Anais, Salvador, SBG, v.4, P.1378-91. 